\title{
Austenitic laser welded I section submitted to torsion and combined torsion plus bending: Assessment of the design rules
}

\author{
K. Lauwens, Y. Liang, O. Zhao, M. Fortan \& B. Rossi \\ Department of Civil Engineering, KU Leuven, Belgium
}

\begin{abstract}
Stainless steel is increasingly used as a construction material in a range of engineering applications. Significant progress in the development of structural design guidance has been made in recent years. However, not much attention has been given to the behaviour of members subjected to torsion or combined torsion plus bending. This paper describes a preliminary study of the structural behaviour of laser welded stainless steel members subjected to these kind of loads. First of all, a brief review of the current international design standards for (stainless) steel members submitted to torsion and combined torsion plus bending is made. Thereupon, previous experimental studies on members submitted to combined torsion plus bending are summarised. A finite element model of an austenitic laser welded I section is then presented. The results of the aforementioned experiments and the numerical model are then employed to assess the current codified design provisions, of which the shortcomings are highlighted.
\end{abstract}

\section{INTRODUCTION}

Stainless steel is gaining increasing use as a construction material, rather than simply a decorative material, in a range of engineering applications, owing principally to its favourable mechanical properties, good ductility and excellent resistance against corrosion and fire. Recently, a new manufacturing technology 'laser fusion' is used to produce stainless steel build-up I beams. The welds are made with powerful lasers without the use of filler material, producing very small weld seams and homogenous material properties of the laser welded sections. In addition, laser fused sections generally feature small internal and external radii and can be classified as sharp edged profiles. Moreover, the level of the resulting residual stress is much lower, compared to that from the commonly used arc welding process.

The present paper describes a preliminary study of the structural behaviour of laser welded stainless steel members subjected to pure torsion and combined torsion plus bending. A review and comparative analysis of current international design standards for stainless steel members under torsion and combined torsion plus bending moment is first presented. Previous experimental studies on carbon steel members submitted to combined torsion plus bending are then summarised. The collected data are then employed to assess the current codified design provisions, of which the shortcomings are highlighted. Afterwards, a finite element model of a $140 \times 140 \times 12 \times 10$ laser welded auste- nitic beam is carried out. The numerical results are then further employed to assess the theoretical predictions.

\section{DESIGN RULES FOR STEEL I SECTIONS}

\subsection{Elastic theory for torsion}

The elastic theory to calculate the torsional stresses on thin-walled beams was developed by Vlasov (1961) and further elaborated by Timoshenko \& Gere (1961), Kollbruner \& Basler (1969) and Galambos (1968). Depending on the type of crosssection, the boundary conditions and the type of loading, the member is in a state of uniform torsion (St. Venant torsion $\mathrm{T}_{t}$ ) or non-uniform torsion (St. Venant $T_{t}$ and warping torsion $T_{w}$ ). St. Venant torsion induces shear stresses $\tau_{t}$, while warping torsion generates both normal $\sigma_{w}$ and shear $\tau_{w}$ stresses.

$T=T_{t}+T_{w}=G I_{T} \phi^{\prime}-E I_{w} \phi^{\prime \prime \prime}$

Where $G$ is the shear modulus, $E$ is the Young's modulus, $I_{T}$ is the St. Venant torsion constant, $I_{w}$ is the warping constant and $\phi$ is the angle of twist.

The torsional stresses are visualized in Figure 1. The St. Venant shear stresses are largest at the edges and can be determined with eq. 2, where $t$ is $t_{f}$ or $t_{w}$ as appropriate. The warping normal stress can be determined by eq. 3 , where $W_{n s}$ is the normalized warping function at point $s$. For sym- 


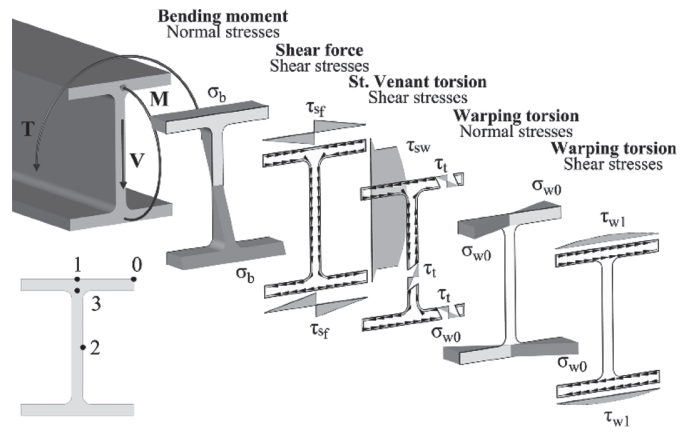

Figure 1. Torsional stresses for an I section.

metric I sections, the warping normal stresses are greatest in point 0 . The warping shear stresses are maximum in point 1 for symmetric I sections and can be determined with eq. 4 , in which $\mathrm{S}_{\mathrm{ws}}$ is the warping statical moment at point $s$. The warping normal stresses lead to a bending moment in the flanges, which is the warping moment $M_{w}$.

$$
\begin{aligned}
& \tau_{t}=G t \varphi^{\prime} \\
& \sigma_{w}=E W_{n s} \phi^{\prime \prime} \\
& \tau_{w}=E S_{w s} \phi^{\prime} \\
& M_{w}=E I_{w} \phi^{\prime \prime} /\left(h-t_{f}\right)
\end{aligned}
$$

All these stresses are related to the angle of twist $\phi$ and its first $\phi^{\prime}$, second $\phi^{\prime \prime}$ and third $\phi^{\prime \prime \prime}$ derivatives, and thus can be calculated when the angle of twist and its derivatives are known along the length of the member. The general solution for the angle of twist for a concentrated torsional load $T$ is:

$$
\phi=A+B \operatorname{ch}\left(\frac{x}{a}\right)+C \operatorname{ss}\left(\frac{x}{a}\right)+\frac{T x}{G I_{t}}
$$

For the loading case in this paper, the equation for the angle of twist, in the first part of the beam, is:

$$
\phi=\frac{T a}{G I}\left[\frac{x}{2 a}+\left[\operatorname{sh}\left(\frac{L}{2 a}\right) / \operatorname{th}\left(\frac{L}{a}\right)-\operatorname{ch}\left(\frac{L}{2 a}\right)\right] \operatorname{sh}\left(\frac{x}{a}\right)\right]
$$

Since the beam and the loading are symmetric, the angle of twist is as well.

The following equations contain the torsional properties for doubly symmetric I sections, i.e. the St. Venant torsion constant $I_{t}$ (since the sections are laser welded, no correction term for the junction is necessary), the warping constant $I_{w}$, the torsional bending constant $a$, the normalized warping function at point $0 W_{n 0}$ and the warping statical moment at point $1 S_{w l}$.

$$
\begin{aligned}
& I_{t}=\left[2 b t_{f}^{3}+\left(h-2 t_{f}\right) t_{w}^{3}\right] / 3 \\
& I_{w}=t_{f} b_{f}^{3}\left(h-t_{f}\right)^{2} / 24 \\
& a=\sqrt{\left(E I_{w}\right) /\left(G I_{t}\right)} \\
& W_{n 0}=\left(h-t_{f}\right) b_{f} / 4 \\
& S_{w 1}=\left(h-t_{f}\right) b_{f}^{2} t_{f} / 16
\end{aligned}
$$

Since the force $P$ (Figure 3 ) acts vertically, the forces modify with the angle of twist due to second order effects. First of all the eccentricity changes from $e$ to $h / 2 \sin (\phi)+e \cos (\phi)$, leading to a modified torsional moment. Furthermore, the force $P$ has to be split up into a force parallel to the web $P \cos (\phi)$ and a force parallel to the flanges $P \sin (\phi)$, thus not only a major, but also a minor axis bending moment occurs. In this paper, an asterisk (*) is used to indicate these modified forces.

\subsection{Eurocode 3}

\subsubsection{Pure torsion}

According to EN 1993-1-1 §6.2.7(1), the total torsional moment $T_{E d}$ should-obviously-be lower than the torsional resistance $T_{R d}$. This statement can only be applied if distortional deformations may be disregarded, yet the code does not say when this is the case. Furthermore the design rules fail to mention how to calculate the torsional resistance $T_{R d}$. Despite not specifying a way to calculate the torsional resistance $T_{R d}$, the Eurocode allows the use of the following Yield Criterion (YC) (eq. 13).

$$
\begin{gathered}
\left(\frac{\sigma_{x, E d}}{f_{y} / \gamma_{M 0}}\right)^{2}+\left(\frac{\sigma_{z, E d}}{f_{y} / \gamma_{M 0}}\right)^{2}-\left(\frac{\sigma_{x, E d}}{f_{y} / \gamma_{M 0}}\right) \\
\left(\frac{\sigma_{z, E d}}{f_{y} / \gamma_{M 0}}\right)+3\left(\frac{\tau_{E d}}{f_{y} / \gamma_{M 0}}\right)^{2} \leq 1
\end{gathered}
$$

The Eurocode specifies that the total torsional moment $T_{E d}$ should be considered as the sum of the St. Venant torsion $T_{t, E d}$ and the warping torsion $T_{w, E d}$ and that they may be determined from the total torsional moment by elastic analysis. The shear stresses $\tau_{t, E d}$ due to St. Venant torsion and the normal $\sigma_{w, E d}$ and shear stresses $\tau_{w, E d}$ due to warping torsion should be taken into account. The paragraph $\$ 6.2 .7(7)$ allows to neglect the effects of St. Venant torsion for open sections. However, not only the type of cross-section, but also the length of the member has an influence on the importance of St. Venant and warping torsion. For long I beams, the St. Venant torsion cannot be neglected (Melcher \& Karmazínová 2012). 


\subsubsection{Combined loads}

For combined torsion and bending, §6.2.7(6) allows to determine the plastic moment resistance of a cross-section, however does not offer an interaction criterion, but only says that the torsion effects $B_{E d}$ should be derived from elastic analysis. The bimoment $B_{E d}$ is the product of the centre-tocentre distance between the flanges and the warping moment $M_{w, E d}$. However when Eurocode refers to the bimoment, it refers to the stresses due to warping torsion (Hughes et al. 2011).

For combined shear force and torsion, the plastic shear resistance should be reduced to $V_{p l, T, R d}$. For I sections, this reduction is based on the ratio of the shear stress due to St. Venant torsion and the allowable shear stress, even though $\$ 6.2 .7(7)$ says that the effects of St. Venant torsion may be neglected. For combined bending, shear and torsion, the moment resistance should be calculated using a reduced yield strength $(1-\rho) f_{y}$, where $\rho$ is given by eq. 14. When, in addition to the latter forces, an axial force is present too, the combination of moment and axial force should be calculated using the same reduced yield strength.

$$
\rho=\left(2 V_{E d} / V_{p l, T, R d}-1\right)^{2}
$$

Applying the latter rules would mean that the bending moment doesn't have to be reduced when a combination of a moment and a torque without a shear force is present. Lastly, second order effects, which will occur when torsion is induced due to an eccentric vertical transverse force, are completely disregarded.

Following the guidelines of Eurocode 3, the most appropriate way to check the resistance of a member when torsion is involved seems to be the yield criterion (eq. 13). As a consequence, it is not possible to take the plastic resistance into account. For open sections, this will not be a problem in practice, since the angle of twist corresponding to the yield strength will almost always be too large to be allowed in the Serviceability Limit State (SLS) (Melcher 1996). Nevertheless, this is a very fundamental concept, which is missing in the Eurocode.

\subsubsection{Supplementary rules}

The supplementary rules for cold-formed members and sheeting give clearer guidelines for torsion. Eurocode 3 Part 1-3 limits the total direct stress $\sigma_{\text {tot Ed }}$ to $f_{y a} / \gamma_{M 0}$ and the total shear stress $\tau_{\text {tot }, E d}$ to $f_{y a} l$ $\left(\gamma_{M 0} \sqrt{3}\right)$. Furthermore the stresses should satisfy eq. 15 , which is an adaptation of the yield criterion. $\sigma_{t o t, E d}$ and $\tau_{t o t, E d}$ are the sum of, respectively, the direct stresses and the shear stresses due to bending, axial force, transverse shear force, St. Venant torsion and warping torsion and should be calculated using either the effective cross-section or the gross cross-section.

$$
\sqrt{\sigma_{t o t, E d}^{2}+3 \tau_{t o t, E d}^{2}} \leq 1.1 f_{y a} / \gamma_{M 0}
$$

There are no additional provisions concerning torsion in the supplementary rules for stainless steel (EN1993-1-4) or high strength steel (EN19931-12), nevertheless the non-linear stress-strain behaviour of stainless steel necessitates specific design rules, as evidenced in paragraph 4 .

\subsubsection{SCI P385}

In publication 385 (Hughes et al. 2011), the Steel Construction Institute (SCI) gives guidance on the verification of the combined effects due to bending and torsion to Eurocode 3. The publication gives an elastic and a plastic verification. For both, a distinction is made between open and closed section. The elastic verification (SCI El.) for open sections (eq. 16) is a linear interaction between the major axis bending moment, the minor axis bending moment (due to the rotation of the section) and the warping moment.

The plastic verification (SCI Pl.) for I and $\mathrm{H}$ sections is given by eq. 17. It should be noted that the angle of twist will be much larger than the elastic value, thus eq. 7 is no longer applicable. However, the elastic value will presently be used for comparison, which should give an overestimation of the capacity. Furthermore, the plastification affects the distribution of the torsional moment leading to a reduced value of the warping moment, thus its evaluation through the elastic analysis represents a conservative overestimation.

$$
\begin{aligned}
& \frac{M_{y, E d}}{M_{y, e l, R d}}+\frac{M_{z, E d}}{M_{z, e l, R d}}+\frac{M_{w, E d}}{M_{f, e l, R d}} \leq 1 \\
& \left(\frac{M_{y, E d}}{M_{y, p l, R d}}\right)^{2}+\frac{M_{z, E d}}{M_{z, p l, R d}}+\frac{M_{w, E d}}{M_{f, p l, R d}} \leq 1
\end{aligned}
$$

where $M_{f, e l, R d} \approx M_{z, e l, R d} / 2$ and $M_{f, p l, R d} \approx M_{z, p l, R d} / 2$.

The shear force due to warping is given by $T_{w, E d} /$ $\left(h-t_{f}\right)$ and should be checked against the shear resistance of the flanges. However, this value is usually much less than the plastic shear resistance and thus its effect on the moment resistance may be neglected. The shear stresses due to St. Venant torsion are accounted for by reducing the plastic shear resistance of the web according to $\$ 6.2 .7(9)$.

\subsubsection{French annex of 1998}

Back in 1998, France had an informative national annex to EN 1993-1-1 on the calculation of the torsional resistance, which is not anymore included. 
This annex included a linear interaction criterion, in which the modification of the loads caused by the rotation due to torsion and the deformations due to bending had to be taken into account. For class 1 or 2 cross-sections, the resistance was to be checked as follows:

$$
\frac{\frac{N_{S d}}{A f_{y}}}{\gamma_{M 1}}+\frac{M_{\phi y, S d}}{\frac{W_{p l, y, R} f_{y}}{\gamma_{M 1}}}+\frac{M_{\phi z, S d}}{\frac{\alpha_{T} W_{e l, z, R d} f_{y}}{\gamma_{M 1}}}+\frac{\sigma_{\phi x, E d}}{\frac{\alpha_{T} f_{y}}{\gamma_{M 1}}} \leq 1
$$

where $\alpha_{T}=W_{p l, z} / W_{e l, z}$ is limited to 1.25 for I or $\mathrm{H}$ sections. For class 3 cross-sections, the elastic section modulus is used instead of the plastic section modulus.

The resistance of the cross-section to a combination of shear force and torsion was checked through the condition $\beta_{V} \leq 1$, provided in eq. 19 for an I-profile. The reduction factor for the effect of shear on the moment resistance $\rho$, which was then calculated as $\left(2 \beta_{V}-1\right)^{2}$, could also be applied in the presence of torsion without a shear force. The yield strength in eq. 18 for both the strong and the weak axis bending moment was reduced to $(1-\rho) f_{y}$ when $\beta_{V}$ is greater than 0.5 .

$$
\beta_{V}=\frac{V_{S d} / A_{V}}{\left(f_{y} / \sqrt{3}\right) / \gamma_{M 0}}+\left(\frac{\tau_{t, E d}}{1,25\left(f_{y} / \sqrt{3}\right) / \gamma_{M 0}}\right)^{2}
$$

\subsection{ANSI/AISC 360}

The Specification for Structural Steel Buildings contains relatively extensive rules for Hollow Structural Sections (HSS). It gives equations for the torsional strength, according to the limit states of torsional yielding and torsional buckling, as well as an interaction formulae for torsion, shear, flexure and/or axial force. However for open sections, the guidelines are limited to the consideration of three limit states: yielding under normal stress $f_{v}$, yielding under shear stress $0,6 f_{y}$ and buckling. The internal stresses should be determined by elastic stress analysis based on established theories of structural mechanics. Reference is made to AISC Design Guide 9 (Seaburg \& Carter 2003). In the provisions, additionally to ANSI/AISC 360 rules, a conservative interaction equation is given when it is unclear which limit state is dominant.

\subsection{AISI S100}

For a combination of bending and torsion, the North American Specification for the Design of Cold-Formed Steel Structural Members multiplies the moment resistance by a reduction factor $R$. This reduction factor is the normal stresses due to bending alone, divided by the combined stresses due to both bending and torsional warping at the point of maximum combined stress along the cross-section. This approach is similar to an interaction based on normal stresses. The resistance of a member subjected to torsion without a bending moment is completely disregarded.

\section{EXPERIMENTS FROM LITERATURE}

No torsion or combined torsion plus bending test conducted on stainless or high strength steel members was found in the literature, thus a comparison is made with carbon steel members. Estabrooks \& Grondin (2008) and Tusnin \& Prokic (2015) conducted experiments on simply supported beams with free warping restraint conditions, like the one modelled in this paper (Figure 3). Estabrooks \& Grondin (2008) tested 6 beams with a length of $4 \mathrm{~m}, 3 \mathrm{~W} 250 \times 67$ and $3 \mathrm{~W} 250 \times 73$ sections, with different eccentricities, leading to various moment-to-torque ratios $\left(\mathrm{M}_{\text {test }} / \mathrm{T}_{\text {test }}\right)$. Tusnin \& Prokic (2015) tested 6 12B1 sections, with the same eccentricity and different lengths, also leading to various moment-to-torque ratios. The results of the comparison can be seen in Figure 2 where the test-to-predicted torque is given versus $\mathrm{M}_{\text {test }} / \mathrm{T}_{\text {test }}$. The plastic verification of the SCI publication provides the best results with an average of the

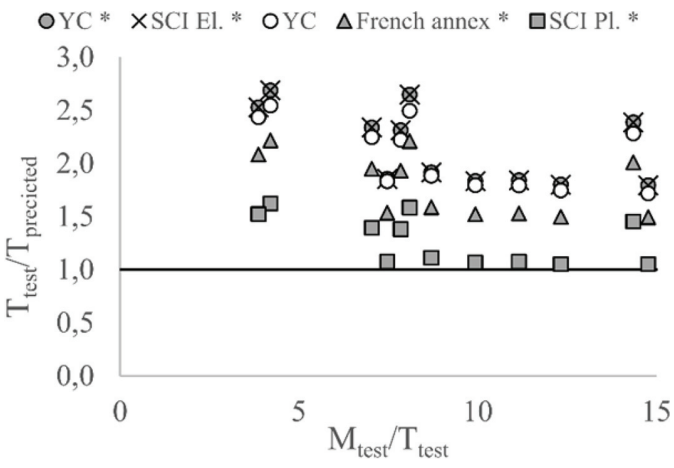

Figure 2. Comparison of test results with design rules.

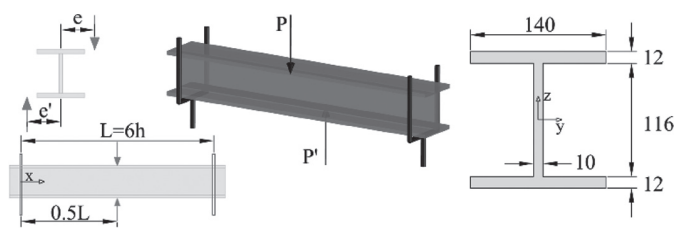

Figure 3. Dimensions and loading case. 
test-to-predicted torque of 1.28 and a standard deviation of 0.23 .

\section{NUMERICAL MODELLING}

One austenitic (grade EN1.4301/304) laser welded class $1 \mathrm{I}$ section is used as an example. The dimensions of this cross-section as well as the loading case are illustrated in Figure 3. The considered profile was analysed using the general-purpose finite element analysis package ABAQUS.

\subsection{Numerical modelling considerations}

The four-noded S4R element employing a reduced integration scheme was applied, which enables finite membrane strain and has shown good performance in the modelling of thin-walled structures. An element size equal to half of the profile thickness was assigned to the shell model. The two-stage Ramberg-Osgood (R-O) material model (Gardner 2005), which provides excellent agreement with experimental stress-strain data, up to the strain range for practical modelling and design of stainless steel members, was adopted to represent the nonlinear stress-strain relationship of austenitic stainless steel:

$$
\begin{aligned}
& \varepsilon=\frac{\sigma}{E}+0.002\left(\frac{\sigma}{\sigma_{0.2}}\right)^{n} \quad \text { for } \sigma \leq \sigma_{0.2} \\
& \varepsilon=\frac{\sigma-\sigma_{0.2}}{E_{0.2}}+\left(0.008-\frac{\sigma_{1.0}-\sigma_{0.2}}{E_{0.2}}\right) \\
& \left(\frac{\sigma-\sigma_{0.2}}{\sigma_{1.0}-\sigma_{0.2}}\right)^{n_{0.2,1.0}}+\varepsilon_{t, 0.2}
\end{aligned}
$$

for $\sigma_{0.2} \leq \sigma \leq \sigma_{\mathrm{u}}$

The adopted material properties were taken from previous tests on cold-formed austenitic RHS profiles (Zhao et al. 2015). Note that the same material model is used for the entire cross-section, which ignores the influence of residual stress from the laser welding procedure. The two-stage R-O material model was first obtained and then converted into the format of true stress and log plastic strain in accordance with the requirement by ABAQUS.

Due to symmetry, half of the eccentrically loaded member was modelled. The end boundary conditions are simulated by coupling the displacements and rotation $U_{x}, U_{y}$ and $R_{z}$ of the end section to a reference point, which is located at the midpoint of the bottom flange. Four degrees of freedom of the reference point were restrained, allowing longitudinal translation and rotation about the strong axis only. For pure torsion conditions, the central section was fully coupled to a reference point located at the shear centre on which a torque was applied. For eccentrically loading conditions, the central section was fully coupled to reference points that were offset from the midpoint of the top flange by the denoted eccentricities along the flange, at which symmetric boundary conditions and a vertical concentrated force were applied. A nonlinear static Riks analysis was performed to trace the full load-deformation curves of the FE models.

\subsection{Results and discussions}

The applied torsional moment versus the angle of twist of the member under pure torsion is depicted in Figure 4, from which a long, steady slope is observed, owing to the development of plasticity throughout the cross-section and the member length. The FE prediction is compared to the theoretical predictions in Figure 4. Clearly, the FE model presents a higher torsional resistance than the other methods owing to the consideration of material nonlinearities, allowing the spread of plasticity throughout the cross-section upon first yielding.

Table 1. Material properties.

\begin{tabular}{llllll}
\hline $\mathrm{E}$ & \multicolumn{3}{l}{} & \multicolumn{3}{c}{ R-O } \\
\hline $\mathrm{N} / \mathrm{mm}^{2}$ & $\mathrm{~N} / \mathrm{mm}^{2}$ & $\mathrm{~N} / \mathrm{mm}^{2}$ & $\mathrm{~N} / \mathrm{mm}^{2}$ & $\mathrm{n}$ & $\mathrm{n}^{\prime}{ }_{0.2,1.0}$ \\
\hline 192,550 & 343 & 391 & 605 & 6.7 & 2.4 \\
\hline
\end{tabular}

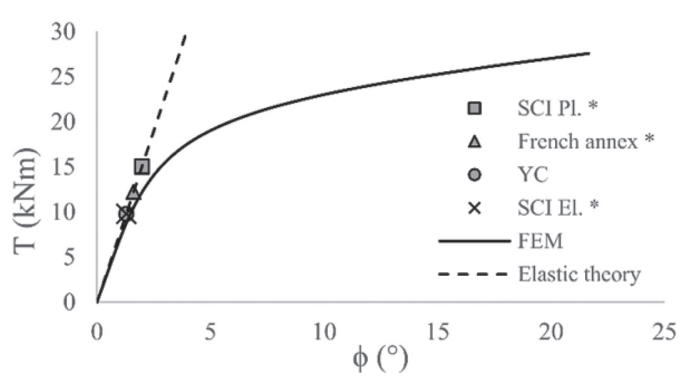

Figure 4. Ultimate torsion in I section under pure torsion.

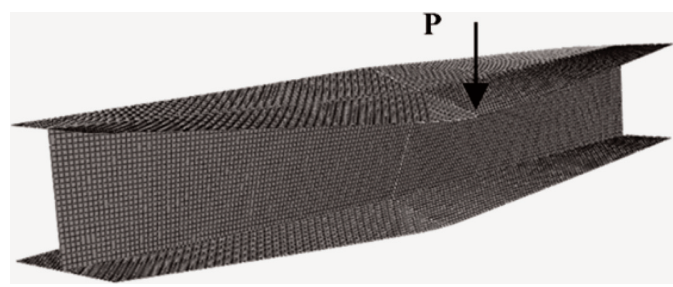

Figure 5. Failure mode for eccentrically loaded case. 
Table 2. Critical concentrated forces for various eccentricities.

\begin{tabular}{lllll}
\hline \multirow{2}{*}{$\begin{array}{l}\text { Model } \\
\text { Eccentricity e (mm) }\end{array}$} & \multicolumn{4}{c}{ Critical force $\mathrm{P}_{\mathrm{u}}(\mathrm{kN})$} \\
\cline { 2 - 5 } & 40 & 60 & 80 & 100 \\
\hline FEM & 422.5 & 337.2 & 275.7 & 231.1 \\
EN 1993-1-1: Yield & 144.4 & 111.5 & 90.8 & 76.6 \\
$\quad$ criterion & & & & \\
$\begin{array}{l}\text { EN 1993-1-1: Yield } \\
\quad \text { criterion * }\end{array}$ & 140.5 & 108.8 & 88.8 & 75.1 \\
EN 1993-1-3 and AISC & 144.4 & 111.5 & 90.8 & 76.6 \\
EN 1993-1-3 * and & 140.5 & 108.8 & 88.8 & 75.1 \\
$\quad$ AISC * & & & & \\
$\begin{array}{l}\text { French annex * } \\
\text { SCI P385 Elastic * }\end{array}$ & 169.0 & 131.8 & 108.2 & 91.8 \\
SCI P385 Plastic * & 233.5 & 186.3 & 153.3 & 129.5 \\
\hline
\end{tabular}

*Calculated with modified forces.

Typical numerical failure mode for laser welded members under eccentric loading are depicted in Figure 5. The value of the force $P$ prior to the overturning of the central section is of engineering concern. Herein, the critical force $P_{u}$ is denoted as the value corresponding to a central twisting angle of $20^{\circ}$, since the rotation continues to increase immensely with a slight increase of the torque. The FE predictions with various initial eccentricities e are listed in Table 2, together with the theoretical predictions.

\section{CONCLUSION}

Primary torsion occurs quite often in engineering practice, e.g. in curved bridges or whenever a force is applied away from the cross-section's shear centre. The design rules recommend to avoid this as much as possible, however this is not always achievable due to architectural or structural requirements, hence it is important that straightforward guidance for the design of members subjected to this kind of load exists. However, the design rules presented in this paper are sometimes incomplete and often confusing.

Both EN 1993-1-1 and AISI S100 reduce the moment resistance based on the torsional stresses, while, at the same time, not indicating how to calculate the torsional resistance. On the other hand, the Eurocode allows to use the yield criterion to check this resistance. ANSI/AISC 360 and EN 1993-1-3 limit the normal and shear stresses separately, the latter also provides a maximum value for a combination of these stresses. SCI P385 contains an elastic and plastic verification for combined forces according to Eurocode 3. The French annex of 1998 includes an interaction criterion which takes the plastic resistance partly into account. The two last methods also do not specify the resistance to pure torsion.

The normal stresses due to warping are far greater than the other stresses and maximum at points where shear is absent, thus the interaction between normal and shear stresses is not decisive. As a result, the interaction criteria based on the YC, i.e. EN 1993-1-1, EN 1993-1-3 and ANSI/ AISC 360, give the same resistance even though ANSI/AISC 360 does not take interaction into account. For the same reason, the elastic verification of the SCI publication is almost identical to the YC.

The inaccuracy of the current design rules was evidenced through the comparison of 12 reference experiments with the theoretical predictions. All the aforementioned design methods underestimate the resistance of a member subjected to torsion or a combination of torsion plus bending, even if, in this evaluation, the assumed angle of twist is calculated with an elastic analysis and used as an overestimation in the plastic verifications.

Furthermore there are no additional provisions concerning torsion in the supplementary rules for stainless steel although the non-linear stress-strain behaviour of stainless steel necessitates specific treatment of this material. This was evidenced through the modelling of a laser welded austenitic stainless steel beam submitted to pure torsion or combined torsion plus bending.

Future work will assess other methods, for example the Partial Internal Force Method (PIFM) (Kindmann \& Vette 2012), the Direct Strength Method (DSM) for torsion (Bian et al. 2016) and the method developed by Trahair (Trahair et al. 2008) by comparing them to an extensive experimental programme on austenitic laser welded and duplex arc welded I beams, supplemented with a parametric study.

\section{REFERENCES}

AISI-S100-12. 2012. North American Specification for the Design of Cold-Formed Steel Structural Members. American Iron and Steel Institute. Washington, D.C.

ANSI/AISC 360-10. 2010 Specification for Structural Steel Buildings. American Institute of Steel Construction. Chicago IL.

Bian, G. et al., 2016. Torsion of cold-formed steel lipped channels dominated by warping response. Thin-Walled Structures, 98, pp 565-577.

EN 1993-1-1. 2015. Eurocode 3: Design of steel structures-Part 1-1: General rules and rules for buildings. European Committee for Standardization. Brussels.

EN 1993-1-1/A2F. 1998. Eurocode 3: Design of steel structures and National Application Document-Part 
1-1: General rules and rules for buildings: Annexe G. European Committee for Standardization. Brussels.

EN 1993-1-3. 2011. Eurocode 3: Design of steel structures-Part 1-3: General rules-Supplementary rules for cold-formed members and sheeting. European Committee for Standardization. Brussels.

EN 1993-1-4. 2015. Eurocode 3: Design of Steel Structures-Part 1-4: General Rules-Supplementary Rules for Stainless Steels. European Committee for Standardization. Brussels.

EN 1993-1-12. 2010. Eurocode 3 - Design of steel structures-Part 1-12: Additional rules for the extension of EN 1993 up to steel grades S 700. European Committee for Standardization. Brussels.

Estabrooks, B.E. \& Grondin, G.Y., 2008. Combined Bending and Torsion of Steel I-shaped Beams.

Galambos, T.V. 1968. Structural members and frames. Prentice-Hall.

Gardner, L. 2005. The use of stainless steel in structures. Progress in Structural Engineering and Materials 7(2): 45-55.

Hughes, A.F., Iles, D.C. \& Malik, A.S. 2011. Design of steel beams in torsion. Berkshire: SCI.

Kindmann, R. \& Vette, J., 2012. General information for and improvements to the design with scheduled torsion according to EN 1993-1-1. Steel Construction, 5(3), pp.183-190.
Kollbrunner, C.F. \& Basler, K. 1969. Torsion in structures: an engineering approach. Berlin: Berlin Springer.

Melcher, J. \& Karmazínová, M., 2012. On Problems of Torsion Analysis of Steel Members with Open Cross Section. Procedia Engineering 40, pp 262-267.

Melcher, J. 1996. "Design limit state: Reality or (science) fiction?", In Chan, S.L. \& Teng J.G. (ed.) Proceedings of the ICASS'96 International conference on advances in steel structures, Hong Kong.

Seaburg, P.A. \& Carter, C.J., 2003. Torsional analysis of structural steel members.

Timoshenko, S.P. \& Gere, J.M. 1961. Theory of Elastic Stability, New York, second edition, McGrawHill.

Trahair, N.S., Bradford, M.A., Nethercot, D.A., Gardner, L., 2008. The Behaviour and Design of Steel Structures to EC3. 4th ed., Taylor \& Francis.

Tusnin, A.R. \& Prokic, M., 2015. Experimental research of I-beams under bending and torsion actions. Magazine of Civil Engineering, 53(1), pp 24-31.

Vlasov, V.Z. 1961. Thin-walled Elastic Beams. Jerusalem Israel Program for Scientific Translations.

Zhao, O., Rossi, B., Gardner L. \& Young, B., 2015. Behaviour of structural stainless steel cross-sections under combined loading_-Part I: Experimental study. Engineering Structures 89, pp 236-246. 